\title{
Исследование мощности люминесценции экситонов и примесно-дефектных центров, возбуждаемых с помощью двухфотонного поглощения
}

\author{
() А.А. Гладилин, В.П. Данилов, Н.Н. Ильичев, В.П. Калинушкин, М.И. Студеникин, \\ О.В. Уваров, В.А. Чапнин, А.В. Рябова, А.В. Сидорин, Э.С. Гулямова, \\ В.В. Туморин, П.П. Пашинин
}

Институт общей физики им. А.М. Прохорова Российской академии наук, 119991 Москва, Россия

E-mail: ilichev@kapella.gpi.ru

Поступила в Редакцию 18 апреля 2019 г.

В окончательной редакции 3 сентября 2019 г.

Принята к публикации 4 сентября 2019 г.

\begin{abstract}
На примере монокристаллов $\mathrm{ZnSe}: \mathrm{Fe}^{2+}$ экспериментально и теоретически исследуется влияние средней мощности фемтосекундного лазерного излучения на среднюю мощность люминесценции экситонов и примесно-дефектных центров при двухфотонном возбуждении электронной системы кристалла. Экспериментально показано, что средняя мощность люминесценции экситонов кристалла в исследованном диапазоне мощностей возбуждения пропорциональна 4-й степени средней мощности возбуждающего излучения. Средняя мощность люминесценции примесно-дефектных центров имеет квадратичный характер. Построена теория, объясняющая наблюдаемые экспериментально зависимости. Отмечается, что характер зависимости люминесценции кристалла от мощности накачки при двухфотонном возбуждении может быть использован для оценки степени загрязнения кристалла примесно-дефектными центрами.
\end{abstract}

Ключевые слова: полупроводники, двухфотонное возбуждение люминесценции.

DOI: $10.21883 /$ FTP.2020.01.48770.9143

\section{1. Введение}

Информативным методом исследования кристаллов является двухфотонная и многофотонная спектроскопия $[1,2]$, позволяющая изучать спектрально-кинетические характеристики люминесценции активных центров и дефектов не только в приповерхностном слое, но и в объеме исследуемых образцов, и, следовательно, соотносить характер изменения центров люминесценции с концентрационным профилем легирующего элемента. Развитием этого метода является двухфотонная конфокальная микроскопия $[3,4]$, которая сочетает достоинства двухфотонной спектроскопии с возможностями современных конфокальных микроскопов.

Характеристики этих приборов и развитое математическое обеспечение позволяют, используя двухфотонное возбуждение неравновесных носителей заряда, быстро снимать „Плоские“ и „объемные“ карты люминесценции в полупроводниковых кристаллах на глубинах до нескольких мм с пространственным разрешением в несколько мкм $[5,6]$.

Двухфотонная конфокальная микроскопия (ДФКМ) в настоящее время активно используется нами для исследования примесно-дефектного состава и его пространственного распределения в кристаллах $\mathrm{ZnSe}$, легированных железом. Этот материал используется в качестве активной среды перестраиваемых лазеров среднего инфракрасного (ИК) диапазона (4-5 мкм) [7-9].
Эффективное использование ДФКМ требует детального понимания процессов генерации и рекомбинации неравновесных носителей, в частности влияния мощности подсветки на мощность межзонной и экситонной люминесценции и люминесценции через примеснодефектные центры (ПДЦ). В ряде работ [10,11] сообщалось о наблюдении степенной зависимости мощности экситонной люминесценции от мощности накачки с показателем степени $>2$ в кристаллах $\mathrm{ZnSe}$ при двухфотонной генерации неравновесных носителей. Схожие результаты были получены авторами данной работы при исследовании кристаллов $\mathrm{ZnSe}: \mathrm{Fe}^{2+}$ с помощью ДФКМ. Авторы работы [11] связывают повышение показателя степени процесса с возможностью реализации условий для усиления экситонной люминесценции (суперлюминесценции). Однако оценки, проведенные в случае возбуждения неравновесных носителей с помощью ДФКМ, показали, что энергия возбуждения образцов фемтосекундными импульсами и длина области инверсной населенности слишком малы для развития заметных эффектов усиления экситонной люминесценции.

В настоящей работе проведены экспериментальные и теоретические исследования зависимости мощности двухфотонно возбуждаемой люминесценции экситонов и примесно-дефектных центров в кристаллах $\mathrm{ZnSe}: \mathrm{Fe}^{2+}$ от мощности возбуждения и дано объяснение наблюдаемых экспериментально зависимостей. 

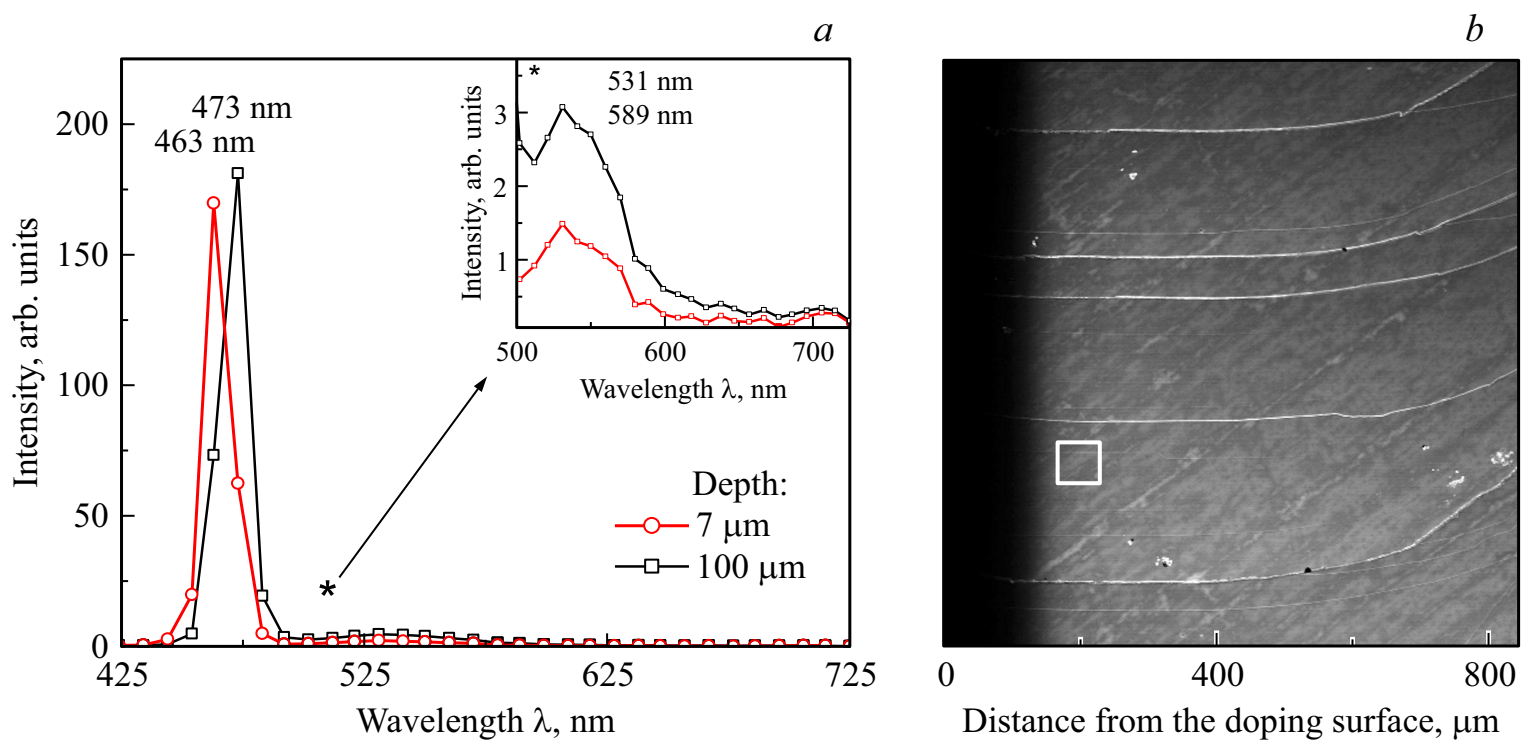

Рис. 1. Спектры люминесценции (a) при двухфотонном возбуждении кристаллов $\mathrm{ZnSe}$ : Fe на глубине 7 и 100 мкм от поверхности кристалла при одинаковой концентрации, снятые в области, выделенной белым квадратом на карте поперечного сечения распределения мощности люминесценции $(b)$. Карта снята на глубине 7 мкм на длине волны 473 нм. На вставке $(a)$ : увеличенная область спектра, соответствующая излучению ПДЦ. Температура измерений — комнатная.

\section{2. Эксперимент}

В данной работе исследовались монокристаллы ZnSe, легированные $\mathrm{Fe}^{2+}$ методом термодиффузии с поверхности при температуре $850^{\circ} \mathrm{C}$ в течение 216 ч в атмосфере аргона. Размер кристалла $1.5 \times 10 \times 10$ мм, глубина диффузии $\mathrm{Fe}^{2+}$ оценена как 150 мкм.

Для регистрации спектров фотолюминесценции (ФЛ) при комнатной температуре использовался конфокальный микроскоп фирмы Carl Zeiss LSM 710 NLO. Двухфотонное возбуждение осуществлялось лазером с перестраиваемой длиной волны в диапазоне $0.71-1.05$ мкм (использовалось излучение с длиной волны 0.8 мкм). Длительность импульса составляла 150 фс, частота 80 МГц. Средняя мощность излучения, падавшего на образец, варьировалась. Спектры люминесценции регистрировались в диапазоне 440-725 нм со спектральным разрешением 10 нм. Эти параметры хорошо подходят для исследования кристаллического $\mathrm{ZnSe}$, ширина запрещенной зоны которого составляет при комнатной температуре $\sim 2.7$ эВ. Таким образом, на этом приборе возможны эффективная реализация двухфотонного возбуждения и регистрация краевой, экситонной и примесно-дефектной люминесценции.

На рис. 1 представлены типичные для данного типа кристаллов $\mathrm{ZnSe}: \mathrm{Fe}^{2+}$ спектры $(a)$ на глубинах 7 и 100 мкм от поверхности кристалла при одинаковой концентрации железа и карта поперечного сечения распределения мощности люминесценции $(b)$. На вставке (рис. $1, a$ ) показаны спектры в увеличенном масштабе в диапазоне 500-725 нм.

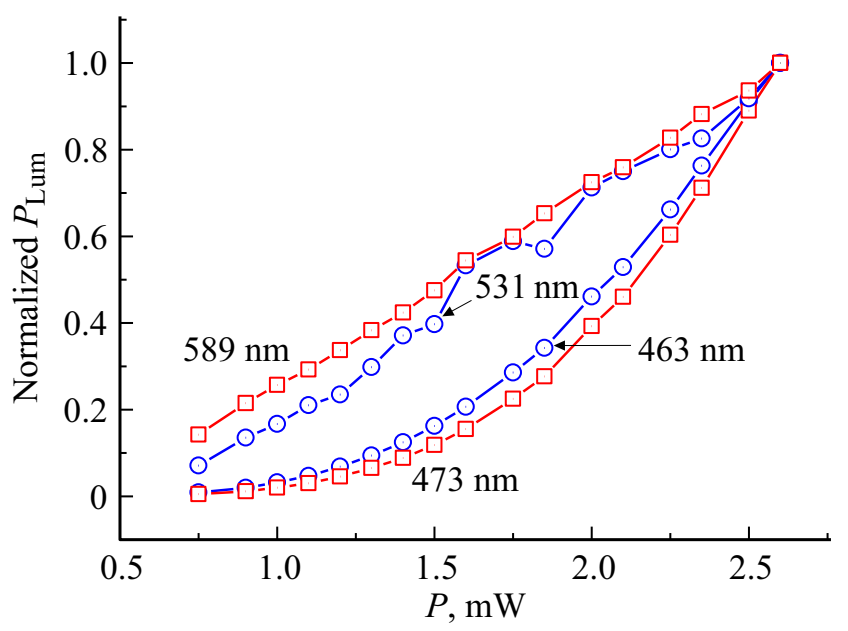

Рис. 2. Нормированная на максимум мощность люминесценции на длинах волн 463, 473, 531 и 589 нм в зависимости от мощности накачки.

В наблюдаемых спектрах выделяются заметные линии экситонной люминесценции при (463 и 473 нм на рис. $1, a)$, а также значительно более слабые линии на длинах волн 531 и 589 нм (рис. $1, a$, вставка). Эти линии обусловлены люминесценцией ПДЦ. Выяснение их природы требует дополнительных исследований. Вероятной причиной образования центров, ответственных за широкую полосу, могут быть собственные точечные дефекты $\left(\mathrm{Zn}_{i}, V_{\mathrm{Zn}}\right)$, образующие комплексы с кислородом и фоновыми примесями $[5,6]$.

Для выяснения физических механизмов возбуждения наблюдаемых линий люминесценции нами были про- 
ведены измерения зависимости мощности линий люминесценции от мощности возбуждающего лазерного излучения. На рис. 2 представлены зависимости нормированной на максимум мощности люминесценции $P_{\text {Lum }}$ для длин волн 463, 473, 531 и 589 нм от мощности возбуждающего излучения $P$.

Если перестроить зависимости, представленные на рис. 2, в логарифмическом масштабе, то наклон прямых, проведенных методом наименьших квадратов через экспериментальные точки, будет равен 3.8 (463 нм), $4.2(473 \mathrm{Hм}), 2.0$ (531 нм) и 1.5 (589 нм). Другими словами, для длин волн 463 и 473 нм мощность люминесценции меняется как 4-я степень мощности возбуждающего излучения, а для длин волн 531 и 589 нм близка к 2-й степени мощности. Такие зависимости были типичны практически для всех исследованных в работах $[5,6]$ кристаллов $\mathrm{ZnSe}: \mathrm{Fe}^{2+}$. Показатель степени зависимости мощности люминесценции экситона от мощности накачки менялся в разных экспериментах, но обычно он был между 3 и 4 и практически всегда $>2$. Как уже отмечалось выше, механизмы, предлагаемые для объяснения этой зависимости в [2,11], не могут быть использованы для объяснения наших результатов.

Для выяснения причин и физических механизмов, способных приводить к 3-й и даже к 4-й степени зависимости мощности экситонной люминесценции от мощности возбуждающего излучения, нами были проведены теоретические расчеты процессов двухфотонного возбуждения электронно-дырочных пар и последующей релаксации возбуждения.

\section{3. Расчет мощности люминесценции экситонов и центров, уровни которых лежат в запрещенной зоне полупроводника, при его двухфотонном возбуждении}

При облучении полупроводника коротким ( 100 фс) мощным лазерным импульсом происходит возбуждение его электронной системы. Рассмотрим следующую модель возбуждения и релаксации возбужденного состояния полупроводника.

Под действием мощного импульса происходит двухфотонное поглощение излучения на переходе валентная зона-зона проводимости. Считаем, что в полупроводнике присутствуют примесные центры, которые ионизуются также за счет двухфотонного поглощения возбуждающего излучения.

Релаксация возбужденного состояния полупроводника происходит в две стадии. На первой стадии, сразу после прохождения короткого мощного лазерного импульса, происходит быстрая, предположительно за времена меньше долей нс, релаксация электронов в зоне проводимости и дырок в валентной зоне, когда пары электрон-дырка образуют экситоны, а часть электронов зоны проводимости заселяет верхние уровни примесных центров. Часть электронов и дырок участвует в рекомбинации с излучением квантов краевой люминесценции. Кроме того, часть электронов зоны проводимости захватывается на верхние уровни центров окраски, которые присутствуют в кристалле, с изменением зарядового состояния такого центра. В спектрах поглощения полупроводника такие центры могут себя и не проявлять. На этой стадии плотность дырок меняется за счет образования экситонов, а также в результате излучения квантов краевой люминесценции. К моменту окончания этой стадии плотность электронов в зоне проводимости равна нулю.

На второй стадии происходит люминесценция экситонов, а также переход электронов с возбужденных уровней примесных центров в основное состояние с излучением квантов люминесценции. Возбужденные центры окраски также переходят в нижнее состояние с излучением квантов люминесценции, после чего теряют заряд, взаимодействуя с дыркой. Предполагаем, что эта стадия относительно медленная, времена релаксации на уровне нс-мкс. По окончании этой стадии полупроводник приходит в состояние, которое он имел до прихода мощного лазерного импульса.

Уравнения для изменения плотности электронов $n_{e}$ в зоне проводимости и плотности дырок $n_{p}$ в валентной зоне сразу после воздействия на среду фемтосекундным лазерным импульсом на первой стадии релаксации возбуждения имеют вид

$$
\begin{gathered}
\frac{d n_{e}}{d t}=-\beta n_{e} n_{p}-\gamma n_{e} n_{c}, \\
\frac{d n_{p}}{d t}=-\beta n_{e} n_{p} .
\end{gathered}
$$

Здесь $\beta$ - коэффициент, отвечающий за скорость образования экситонов и скорость рекомбинации электронов и дырок с излучением квантов краевой люминесценции, $n_{c}$ - плотность уровней в запрещенной зоне, $\gamma-$ коэффициент, определяющий скорость захвата электронов зоны проводимости на уровни, лежащие в запрещенной зоне. Пусть имеется возможность образования нескольких типов экситонов, тогда скорости их образования обозначим как $\beta_{1} n_{e} n_{p}, \beta_{2} n_{e} n_{p}$ и т.д. Пусть также имеет место рекомбинация электронов и дырок с излучением квантов краевой люминесценции, которая происходит со скоростью $\beta_{0} n_{e} n_{p}$. Тогда в уравнения (1а) и (1б) эти члены войдут в виде суммы $\beta n_{e} n_{p}=n_{e} n_{p} \sum_{i} \beta_{i}, i=0,1 \ldots$ Заполнение уровней, расположенных в запрещенной зоне, также возможно по нескольким каналам, поэтому последний член в правой части уравнения имеет вид $\gamma n_{c} n_{e}=n_{e} \sum_{i} \gamma_{i} n_{c i}$, где $\gamma$ и $n_{c}-$ „эффективные“ коэффициенты. Отметим, что по отношению мощностей люминесценции в максимумах линий можно определить, как соотносятся между собой коэффициенты $\beta_{i}$ и $\gamma_{i} n_{c i}$.

Примем, что в начальный момент времени, который определяется сразу после окончания действия фемтосекундного импульса на среду, $n_{e}(0)=n_{p}(0)=n_{0}$. Это 
предположение справедливо, если концентрация примеси, которая ионизуется мощным излучением, невелика.

Из (1б) можно получить уравнение для плотности дырок в зависимости от времени $t$ :

$$
n_{p}(t)=n_{0} \exp \left(-\beta \int_{0}^{t} n_{e} d t\right)
$$

Подставляя (2) в (1a) и решая получившееся уравнение, найдем

$$
\begin{aligned}
n_{e}(t)-n_{e}(0)= & -n_{0}\left[1-\exp \left(-\beta \int_{0}^{t} n_{e} d t^{\prime}\right)\right] \\
& -\gamma n_{c} \int_{0}^{t} n_{e} d t^{\prime} .
\end{aligned}
$$

Обозначая $u(t)=\beta \int_{0}^{t} n_{e} d t^{\prime}$, из (3) получим уравнение для $u(t)$ :

$$
\frac{d u}{d t}=n_{0} \beta \exp (-u)-\gamma n_{c} u
$$

При $t \rightarrow \infty$ уравнение (4) имеет стационарное решение, когда $d u / d t=0$, что по физическому смыслу означает отсутствие электронов в зоне проводимости. Полагая левую часть уравнения (4) равной 0, получим уравнение для нахождения стационарного значения величины $u$ :

$$
\beta n_{0} \exp (-y)=\gamma n_{c} y,
$$

где значение $y=u(t=\infty)$ определено на момент окончания первой стадии релаксации возбуждения в веществе. Отметим, что уравнение (4) имеет стационарное решение, если $\gamma n_{c}>0$.

На второй стадии релаксации происходит высвечивание экситонов и возбужденных уровней, находящихся в запрещенной зоне. Количество квантов люминесценции экситонов, излученных из единицы объема вещества, равно $N_{\mathrm{ex}}=\int_{0}^{\infty}\left(\beta-\beta_{0}\right) n_{e} n_{p} d t$. Учитывая (1a), (1б) и (2), а также $y=\beta \int_{0}^{\infty} n_{e} d t$, получим

$$
N_{\text {ex }}=\left(1-\frac{\beta_{0}}{\beta}\right) n_{0}[1-\exp (-y)]
$$

Уравнение (6) определяет количество квантов, излученных экситонами из единицы объема вещества при релаксации возбуждения в веществе на один импульс возбуждающего излучения.

При лазерном возбуждении материала характеристикой возбуждающего излучения является средняя мощность $P$, которая определяется энергией $E$ лазерного импульса и частотой повторения импульсов $f_{p}: P=E f_{p}$.
Именно эта мощность и измеряется на практике. Значение $n_{0}$ при двухфотонном возбуждении при „умеренных“ уровнях мощности возбуждающего излучения $n_{0} \propto P^{2}$.

Мощность люминесценции экситонов из зоны возбуждения будет $P_{\mathrm{ex}} \propto N_{\mathrm{ex}} f_{p}$. Найдем зависимость мощности люминесценции экситонов от средней мощности накачки.

При малом уровне возбуждения материала, который определяется соотношением $\beta n_{0} / \gamma n_{c} \ll 1$, решение (5) имеет вид $y \propto \beta n_{0} / \gamma n_{c}$ и из (6) имеем

$$
P_{\mathrm{ex}} \propto N_{\mathrm{ex}}=\frac{\left(\beta-\beta_{0}\right)}{\beta} n_{0} y=\frac{\left(\beta-\beta_{0}\right) n_{0}^{2}}{\gamma n_{c}} \propto P^{4} .
$$

Таким образом, из (7) видно, что при низком уровне возбуждения, когда $\beta n_{0} / \gamma n_{c} \ll 1$, мощность люминесценции экситонов пропорциональна 4-й степени средней мощности накачки.

При большом уровне возбуждения, когда $\beta n_{0} / \gamma n_{c} \gg 1$, приближенное решение (5) имеет вид $y \approx$ $\approx \ln \left(\beta n_{0} / \gamma n_{c}\right)-\ln \left[\ln \left(\beta n_{0} / \gamma n_{c}\right)\right]$ и

$$
P_{\mathrm{ex}} \propto N_{\mathrm{ex}}=\left(1-\frac{\beta_{0}}{\beta}\right) n_{0}[1-\exp (-y)] \propto n_{0} \propto P^{2},
$$

т.е. при высоком уровне возбуждения, когда $\beta n_{0} / \gamma n_{c} \gg 1$, мощность люминесценции экситонов пропорциональна 2-й степени средней мощности. Высокий или низкий уровни возбуждения определяются характеристиками кристалла и его качеством, так как в отношение $\beta n_{0} / \gamma n_{c}$ помимо коэффициентов $\beta$ и $\gamma$ входит плотность $n_{c}$ уровней, находящихся в запрещенной зоне. В промежуточном диапазоне уровней возбуждения показатель степени может лежать между 4 и 2.

Мощность люминесценции с уровней, находящихся в запрещенной зоне, определяется выражением

$$
P_{c} \propto \gamma n_{c} \int_{0}^{\infty} n_{e} d t=\gamma n_{c} \frac{1}{\beta} y .
$$

При малых значениях мощности возбуждающего излучения, когда $\beta n_{0} / \gamma n_{c} \ll 1, y \propto \beta n_{0} / \gamma n_{c}$, и из (9) следует, что мощность люминесценции будет пропорциональна 2-й степени мощности возбуждающего излучения,

$$
P_{c} \propto n_{0} \propto P^{2} .
$$

Это отличается от случая экситонной люминесценции, где при малой мощности возбуждения зависимость пропорциональна 4-й степени мощности.

При большом уровне возбуждения, $y \approx \ln \left(\beta n_{0} / \gamma n_{c}\right)$ $-\ln \left[\ln \left(\beta n_{0} / \gamma n_{c}\right)\right]$,

$$
P_{c} \propto \gamma n_{c} \frac{1}{\beta} y \propto A+B \ln (P),
$$

где $A$ и $B-$ некоторые постоянные.

Отметим здесь еще один момент. Релаксация электронного возбуждения с уровней, лежащих в запрещенной зоне, может происходить и без излучения фотона. 
Несмотря на то что в этом случае нет возможности прямо наблюдать процесс релаксации этих уровней, на зависимости мощности люминесценции экситонов от мощности накачки наличие такого процесса должно сказаться. Это дает возможность по такой зависимости оценить качество полупроводника.

\section{4. Сравнение расчета и с экспериментом}

Представленные на рис. 2 зависимости мощности люминесценции от мощности возбуждающего излучения сравнивались с расчетом.

На рис. 3 приведены экспериментальные зависимости мощности люминесценции $P_{\text {Lum }}$ на длинах волн 463 и 473 нм, нормированные на максимум, в зависимости от нормированной на максимальное значение мощности возбуждающего излучения $P$, сплошная линия результаты расчета.

Для сравнения расчета с экспериментом использовалась следующая процедура. Для нахождения величины $y$ из уравнения (5) вводилась переменная $\delta=\sqrt{\beta n_{0} / \gamma n_{c}}$, значение которой пропорционально мощности возбуждающего излучения. Из экспериментальных данных известно отношение $\chi=P_{\max } / P_{\min }$ максимального $\left(P_{\max }\right)$ и минимального $P_{\min }$ значений мощности возбуждающего излучения. Для сравнения с экспериментом диапазон изменения величины $\delta$ определялся так, что отношение максимального значения $\delta_{\max }$ и минимального $\delta_{\min }$ было равно $\chi$. С другой стороны, численное значение $\delta_{\max }$ выбиралось так, чтобы экспериментальное отношение суммарной мощности люминесценции на длинах волн 463 и 473 нм $P_{\text {Lum }}\left(P_{\min }\right) / P_{\text {Lum }}\left(P_{\max }\right)$ было равно отношению $N_{\text {ex }}\left(\delta_{\min }\right) / N_{\text {ex }}\left(\delta_{\max }\right)$, где $N_{\text {ex }}(\delta)$ находится из (6) и (5).

На рис. 3 мощность возбуждающего излучения выражена в единицах $\delta / \delta_{\max }$, что совпадает с нормированной на максимум мощностью возбуждающего излучения $P / P_{\max }$. Мощность люминесценции также нормирована на максимальное значение как для длины волны 463 нм, так и для 473 нм. Численные значения $\delta$ в расчете были $\delta_{\min }=0.15, \delta_{\max }=0.55$, и можно считать, что условие $\beta n_{0} / \gamma n_{c}=\delta^{2} \ll 1$ выполняется. Теоретическая кривая на рис. 3 показывает, что мощность люминесценции пропорциональна 4-й степени мощности возбуждающего излучения.

На рис. 4 представлены зависимости нормированной на максимум мощности люминесценции на длинах волн 531 и 589 нм от нормированной на максимальное значение мощности возбуждающего излучения.

Так как люминесценция на длинах волн 531 и 589 нм соответствует переходам с уровней, лежащих в запрещенной зоне, то расчет мощности люминесценции проводился согласно (9).

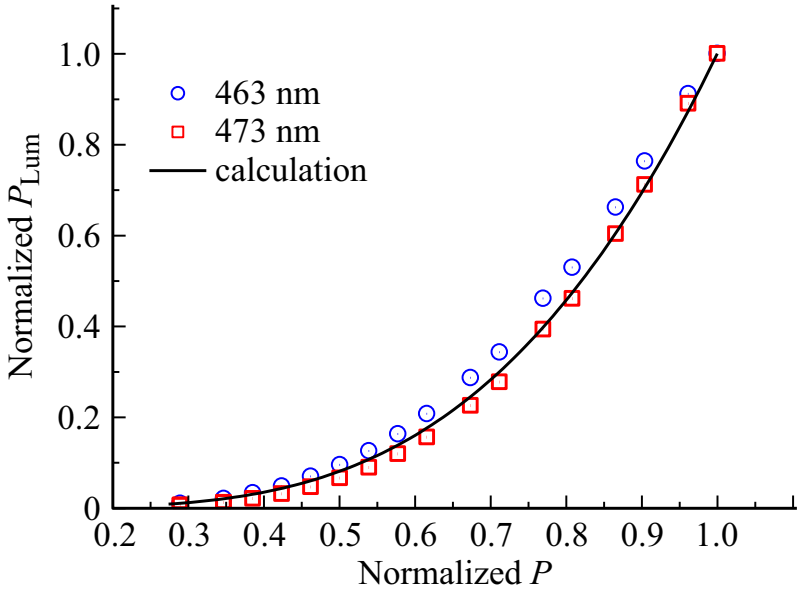

Рис. 3. Нормированная на максимум мощность люминесценции экситонов с длиной волны 463 и 473 нм (точки) и расчет (сплошная линия) в зависимости от нормированной мощности возбуждающего излучения.

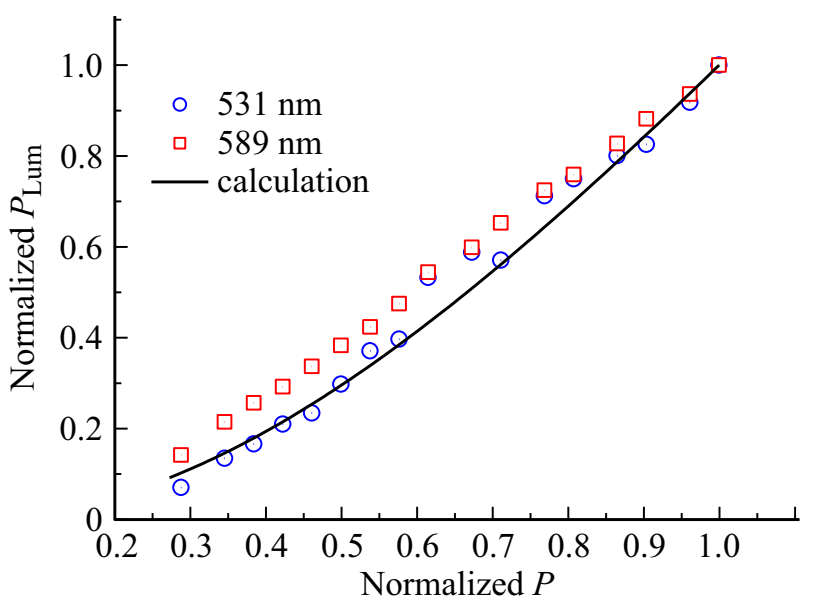

Рис. 4. Нормированная на максимум мощность люминесценции на длинах волн 531 и 589 нм (точки) и расчет (сплошная линия) в зависимости от нормированной мощности возбуждающего излучения.

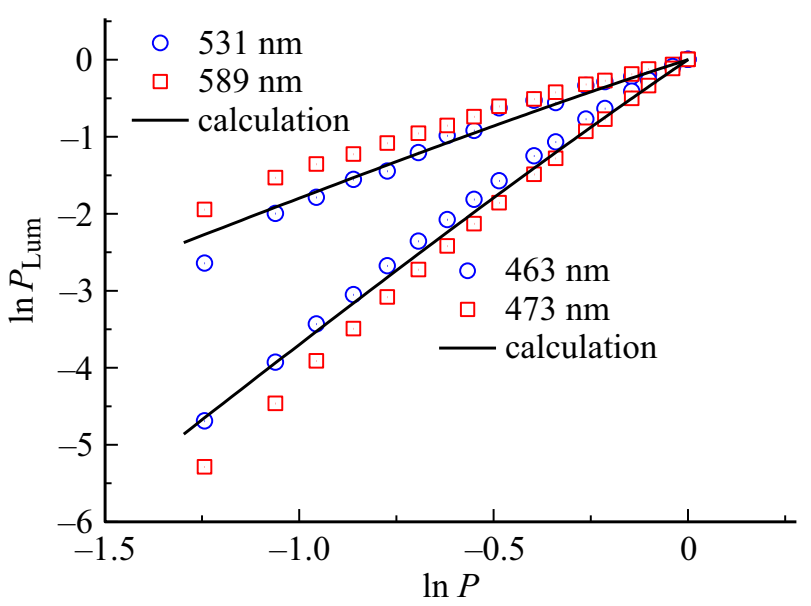

Рис. 5. Зависимости мощности люминесценции от мощности возбуждающего излучения, представленные на рис. 3 и 4, перестроенные в логарифмическом масштабе. Точки - эксперимент, сплошные кривые - расчет. 
На рис. 5 приведены в логарифмическом масштабе представленные на рис. 3 и 4 зависимости мощности люминесценции от мощности возбуждающего излучения. Наклоны прямых, проведенных с применением метода наименьших квадратов через экспериментальные точки на рис. 5, получаются следующими: 3.8 (463 нм), 4.2 (473 нм), 2.0 (531 нм) и 1.5 (589 нм). Другими словами, для длин волн 463 и 473 нм мощность люминесценции меняется как 4-я степень мощности возбуждающего излучения, для длины волны 531 нм - как 2-я степень мощности, а для длины волны 589 нм - как 1.5-я. Можно заключить, что построенная теория хорошо описывает экспериментальные данные.

\section{5. Заключение}

Экспериментально измерена зависимость мощности люминесценции на длинах волн 463, 473, 531 и 589 нм в монокристалле $\mathrm{ZnSe}: \mathrm{Fe}^{2+}$ от мощности возбуждающего излучения. Показано, что эта зависимость имеет степенной характер, причем показатель степени для излучения с длинами волн 463, 473 нм близок к 4, а для излучения с длинами волн 531 и 589 нм лежит в диапазоне между 1.5 и 2.

Построена теория, которая объясняет степенну́ю зависимость мощности люминесценции на разных длинах волн от мощности возбуждающего излучения при двухфотонном возбуждении электронной системы кристалла.

В рамках этой теории показано, что мощность люминесценции экситонов зависит от уровня возбуждения и плотности уровней (например, примесей или дефектов кристаллической решетки), находящихся в запрещенной зоне. При низкой мощности возбуждения зависимость мощности люминесценции имеет вид 4-й степени мощности возбуждающего излучения, при большой - 2-й степени, при промежуточных значениях мощности показать степени лежит между 4 и 2. Переход от одного вида зависимости к другому зависит от качества полупроводника, т.е. от концентрации дефектов кристаллической структуры.

Люминесценция с уровней, лежащих в запрещенной зоне, при малых уровнях возбуждения пропорциональна 2-й степени мощности возбуждающего излучения.

Проведено сравнение полученных экспериментально зависимостей мощности люминесценции от мощности возбуждающего излучения с расчетом. Представлено описание экспериментальных зависимостей расчетом.

Построенная теория указывает на принципиальную возможность контроля качества полупроводника, например, наличия уровней в запрещенной зоне, по характеру зависимости мощности экситонной люминесценции от мощности возбуждающего излучения при двухфотонном возбуждении, причем контроль возможен и в том случае, когда релаксация возбуждения происходит без излучения квантов люминесценции.

\section{Финансирование работы}

Работа выполнена с использованием оборудования центра коллективного пользования „Технологический и диагностический центр для производства, исследования и аттестации микро- и наноструктур“ Института общей физики им. А.М. Прохорова РАН при финансовой поддержке в рамках программы президиума РАН № 5 „Фотонные технологии в зондировании неоднородных сред и биообъектов“, а также при частичной поддержке грантами РФФИ № 19-02-00294 и 18-29-20048.

\section{Конфликт интересов}

Авторы заявляют, что у них нет конфликта интересов.

\section{Список литературы}

[1] S. Hell, E.H.K. Stelzer. Optics Commun., 93(5-6), 277 (1992).

[2] J.W.M. Chona, M. Gu, C. Bullen, P. Mulvaney. Appl. Phys. Lett., 84 (22), 4472 (2004).

[3] В.П. Калинушкин, О.В. Уваров. ЖТФ, 86 (12), 119 (2016).

[4] V.P. Kalinushkin, O.V. Uvarov. JETP Lett., 104, 754 (2016).

[5] Е.М. Гаврищук, А.А. Гладилин, В.П. Данилов, В.Б. Иконников, Н.Н. Ильичев, В.П. Калинушкин, А.В. Рябова, М.И. Студеникин, Н.А. Тимофеева, О.В. Уваров, В.А. Чапнин. Неорг. матер., 52 (11), 1 (2016).

[6] А.А. Гладилин, Н.Н. Ильичев, В.П. Калинушкин, М.И. Студеникин, О.В. Уваров, В.А. Чапнин, В.В. Туморин, Г.Г. Новиков. ФТП, 53 (1), 5 (2019).

[7] S.B. Mirov, V.V. Fedorov, D.V. Martyshkin, I.S. Moskalev, M. Mirov, S. Vasilyev. IEEE J. Select. Topics Quant. Electron., 21, 1 (2015).

[8] A.E. Dormidonov, K.N. Firsov, E.M. Gavrishchuk, V.B. Ikonnikov, S.Yu. Kazantsev, I.G. Kononov, T.V. Kotereva, D.V. Savin, N.A. Timofeeva. Appl. Phys. B, $122(8), 211$ (2016).

[9] С.Д. Великанов, Е.М. Гаврищук, Н.А. Зарецкий, А.В. Захряпа, В.Б. Иконников, С.Ю. Казанцев, И.Г. Кононов, А.А. Манешкин, Д.А. Маликовский, Е.В. Салтыков, К.Н. Фирсов, Р.С. Чуваткин, И.М. Юткин. Квант. электрон., 47 (4), 303 (2017).

[10] Р.А. Балтрамеюнас, А.А. Гладыщук, В.П. Грибковский, Э.П. Куокштис, Г.П. Яблонский. Квант. электрон., 8 (4), 898 (1981).

[11] А.М. Агальцов, В.С. Горелик, И.А. Рахматуллаев. ФТП, 31 (12), 1422 (1997).

Редактор Л.В. Шаронова 


\title{
Study of the luminescence power of excitons and isolated defect centers excited by two-photon absorption
}

A.A. Gladilin, V.P. Danilov, N.N. I' ichev, V.P. Kalinushkin, M.I. Studenikin, O.V. Uvarov,

V.A. Chapnin, A.V. Ryabova, A.V. Sidorin,

E.S. Gulyamova, V.V. Tumorin, P.P. Pashinin

Prokhorov General Physics Institute,

Russian Academy of Sciences,

119991 Moscow, Russia

\begin{abstract}
It is experimentally and theoretically studied the effect of the average power of femtosecond laser radiation on the average luminescence power of excitons and impurity-defect centers upon two-photon excitation of the electron system using the $\mathrm{ZnSe}: \mathrm{Fe}^{2+}$ single crystals as an example. It has been experimentally shown that the average luminescence power of excitons in the investigated excitation power range is proportional to 4th degree of the average exciting radiation power. The average luminescence power of impurity-defect centers is quadratic. The experimental dependencies were explained theoretically. It is noted that the nature of the dependence of the crystal luminescence on the pump power under two-photon excitation can be used to assess the degree of contamination of crystals impurity-defect centers.
\end{abstract}

